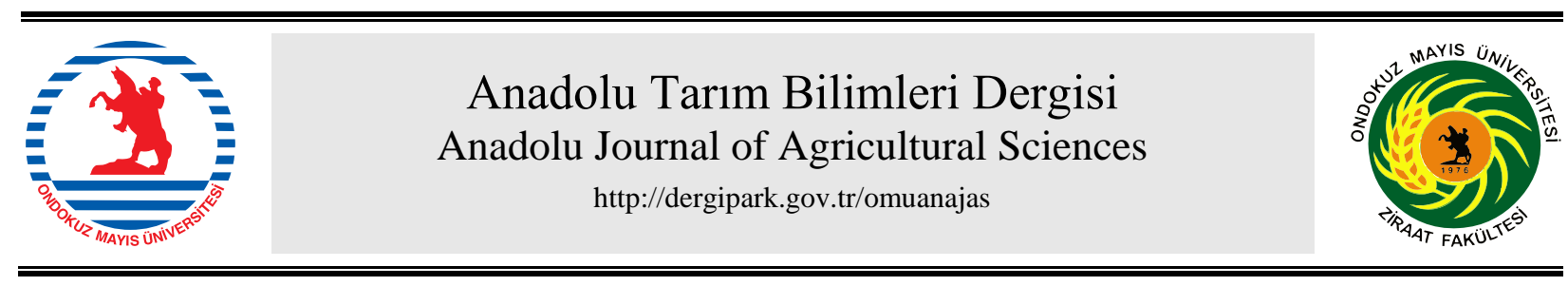

Araştırma/Research

Anadolu Tarım Bilim. Derg./Anadolu J Agr Sci, 34 (2019) ISSN: 1308-8750 (Print) 1308-8769 (Online) doi: 10.7161/omuanajas.461289

\title{
Mekanize fındık hasadı ile toplanan fındığın yatay hava tünelinde taş ve topraktan temizlenme olanaklarının incelenmesi
}

\author{
Kübra Meriç Kalın**, Mehmet Arif Beyhan ${ }^{\mathrm{a}}$ \\ ${ }^{a}$ OMÜ Ziraat Fakültesi Tarım Makinaları ve Teknolojileri Mühendisliği Bölümü, Samsun \\ "Sorumlu yazar/corresponding author: meric.kalin@ hotmail.com
}

Geliş/Received 19/09/2018～Kabul/Accepted 04/04/2019

\begin{abstract}
ÖZET
$\mathrm{Bu}$ çalışmada, mekanize fındık hasadı sırasında yerden toplanan materyal karışımından, taş-toprağın yatay hava tüneli kullanılarak temizlenme olanakları ve gerekli sistem parametrelerinin belirlenmesi amaçlanmıştır. Denemeler, iki farklı karışım oranında (\% 6 taş, \% 6 toprak ve \% 88 oranında tane findık, tekli, ikili, üçlü çotanak ve zuruflu findık (A) ve \% 10 taş, \% 10 toprak ve $\% 80$ oranında tane fındık, tekli, ikili, üçlü çotanak ve zuruflu fındık (B), dört farklı besleme miktarında (500, 750, 1000 ve $\left.1250 \mathrm{kgh}^{-1}\right)$ ve beş farklı hava hızında $\left(25,30,35,40\right.$ ve $\left.45 \mathrm{~ms}^{-1}\right)$ gerçekleştirilmiştir. Denemeler sonucunda A ve B karışımları için en yüksek temizleme etkinliği değerleri sırasıyla 25-30 $\mathrm{ms}^{-1}$ hava hızlarında ve 30-40 cm ürün dökülme mesafelerinde elde edilmiştir. A karışımında taş ve toprak temizleme etkinlikleri sırasıyla \% 91 ve \% 89 olurken, B karışımında \% 89 ve \% 84 olarak elde edilmiştir. Aynı parametreler için kayıp fındık oranları A karışımında \% 10 B karışımında ise \% 9 olmuştur.
\end{abstract}

Examination of the possibility of separation of the hazelnut collected by mechanized hazelnut harvest from stone and soil in horizontal air tunnel

\section{ABSTRACT}

In this study, it was aimed to determine the possibilities of cleaning and the necessary system parameters by using horizontal air tunnel of stone-soil from the material mixture collected from the ground during hazelnut harvesting. The experiments were carried, in two different mixing ratios $(6 \%$ stone, $6 \%$ soil and $88 \%$ seed hazelnut, single, double, triple hazelnut and husk (A) and $10 \%$ stone, $10 \%$ soil and $80 \%$ seed hazelnut, single, double, triple hazelnut and husk, at four different feed rates $\left(500,750,1000\right.$ and $\left.1250 \mathrm{~kg} \mathrm{~h}^{-1}\right)$ and five different air velocities $\left(25,30,35,40\right.$ and $\left.45 \mathrm{~ms}^{-1}\right)$. As a result, the highest cleaning efficiency values for mixtures A and B were obtained at air velocities of 25$30 \mathrm{~m} \mathrm{~s}^{-1}$ and $30-40 \mathrm{~cm}$ product spill distances, respectively. While the stone and soil clearing efficiencies in A mixture were $91 \%$ and $89 \%$, B mixture were $89 \%$ and $84 \%$, respectively. For the same parameters, the loss hazelnut ratios were $9 \%$ in mixture A and $10 \%$ mixture $\mathrm{B}$.

Anahtar Sözcükler: Yatay hava tüneli Seperasyon Findik hasadi Taneli ürün Temizleme etkinliği

\section{Giriş}

Fındık, dünyada, bademden sonra yetiştiriciliği en yaygın yapılan sert kabuklu meyve çeşididir. Ülkemiz yaklaşık 701 bin hektar findık üretim alanıyla dünyada lider konumdadır. Ülkemizin findık ihracatındaki payı yaklaşık 505 bin ton olup dünya findık ihracatının yaklaşık \% 72'sini gerçekleştirmektedir. Yıllık kabuklu findık üretim miktarı yaklaşık 525 bin tondur (FAO, 2014). Findığın tarıma dayalı sanayiye hammadde sağlaması, hammadde, yarı mamul, mamul üretimi ve ticareti aşamalarında istihdam ve katma değer katması, en önemli ihraç ürünlerinden biri olması ülke ekonomisindeki önemini ortaya koymaktadır (Bozoğlu, 1999) . Türkiye'de yetiştirilen findık çeşitleri, genellikle meyveyi sıkıca saran uzun zuruflara sahiptir. $\mathrm{Bu}$ nedenle, olgun meyveler kendiliğinden zuruftan ayrılmamakta ve çotanaklar halinde dökülmektedir. Daldan ve yerden çotanaklar halinde toplanan findıklar açık havada kurutulduktan sonra zuruf soyma işlemine tabi tutulmaktadır. Fındık hasadının, findığın toplanması ve zurufların soyulması işlemlerini kapsadığı dikkate alındığında zuruf soyma makinalarının elle toplanmış findığa göre tasarlanmış olması ve mekanik olarak toplanan findıkların muhtemel çerçöp içermesi nedeniyle zuruf soyma makinalarının performansını 
etkilemektedir. Son yıllarda yerel imalatçılar tarafından sinırlı sayıda da olsa mekanik ve pnömatik toplama üniteli findık hasat makinaları imal edilmekte ve bu makinalarla toplanan findık taş, toprak vb. yabancı materyal içerdiğinden findığın temizlenmesi ayrı bir iş olarak karşımıza çıkmaktadır.

Beyhan (1992), Türkiye koşullarına uygun bir aspirasyonlu findık hasat makinası tasarımı ve imalatını yaptığı çalışmasında, makinayla çalışmada ayırıcıda toprağın ayrılamadığını ve kuru otun ayrılma yüzdesinin ise düşük olduğunu saptamıştır. $\mathrm{Bu}$ durumun, ot parçalarının zuruflu findıklara takılarak çökmesinden kaynaklandığını belirtmiştir. Kuru koşullarda ayırıcının toplam ayırma etkinliğini \% 35.36 olarak tespit etmiş, toprak olmaksızın diğer hafif materyaller için ayırma etkinliğinin \% 60.55 oranında gerçekleştiğini, yağışı koşullarda ise toplam ayırma etkinliğinin \% 25'e, toprak dikkate alınmadığında diğer hafif materyallerin ayırma etkinliğinin ise \% 35.60'a düştüğünü bildirmiştir. Ayrıca, zeminden toplanan yabancı materyallerin büyük bölümünü ise toprağın oluş̧urduğunu tespit etmiştir.

Yine, Sauk (2016), Türkiye'de düz ve düze yakın arazilerde yetiştirilen findığın mekanik hasat olanaklarını incelediği çalışmasında, prototip imalatı yapılan mekanik etkili toplama üniteli findık toplama makinasının, farklı bahçe verimi koşullarında alan iş başarısının $0.158-0.102 \mathrm{hah}^{-1}$ ve ürün iş başarısının 124.83-1322.08 $\mathrm{kgh}^{-1}$, yabanc1 materyal ayıklama etkinliğinin \% 96.61-95.62 olduğunu belirlemiştir. Toplanan yabancı materyallerin \% 68.60'inın toprak ve dal parçasından oluştuğunu tespit etmiştir.

Sarig ve ark. (1974), meyvelerin ve yabanc1 materyallerin aerodinamik özelliklerindeki farklılıktan yararlanılarak, namlu hazırlığ 1 sirasında yapraklar ve diğer yabanc1 materyalleri uzaklaştıracak sistemler üzerinde yaptıkları çalışmalarında, $9.15 \mathrm{~ms}^{-1}$ lik (materyal akışına göre ters yönlü) bir hava hızı ile önemli miktarda yaprağın uzaklaştırıldığını, iyi hazırlanmış zemin koşullarında süpürücüden süpürme etkinliğinin \% 99 olduğunu saptamışlardır.

Simonyan ve Yiljep (2008), sorgumda harman sonrası tane dağılımını ve temizleme etkinliğini belirlemek amaciyla sabit harman makinası geliştirmişlerdir. Temizleme kayıplarının, besleme hızı ve hava hızının artması ile arttığını ve en yüksek harmanlama etkinliğinin \% $\quad 99.85$ olduğunu bildirmişlerdir. Hava hızındaki artışla kayıp oranında artma meydana geldiğini ve farklı besleme miktarlarında \% 54'e kadar kayıp ürün olduğunu tespit etmişlerdir.

$\mathrm{Bu}$ çalışmada, makine ile hasat edilen findığın yabanc1 materyallerden temizlenmesi için yatay hava tüneli kullanılmış, bu sisteme ait işletme parametreleri belirlenmeye çalış1 lmıştır.

\section{Materyal ve Yöntem}

\subsection{Materyal}

Denemeler Yomra cinsi findık kullanılarak Ondokuz Mayıs Üniversitesi, Ziraat Fakültesi Tarım Makinaları ve Teknolojileri Mühendisliği Bölümü atölyesinde yürütülmüştür. Fındıkların nem içeriği hasat zamanındaki nem içeriği baz alınarak \% 25 olarak ayarlanmıştır.

Çalışma için tasarlanıp imalatı yaptırılan yatay hava tüneli, besleme ünitesi, temizleme ünitesi ve vantilatör olmak üzere üç ana üniteden oluşmaktadır (Şekil 1).

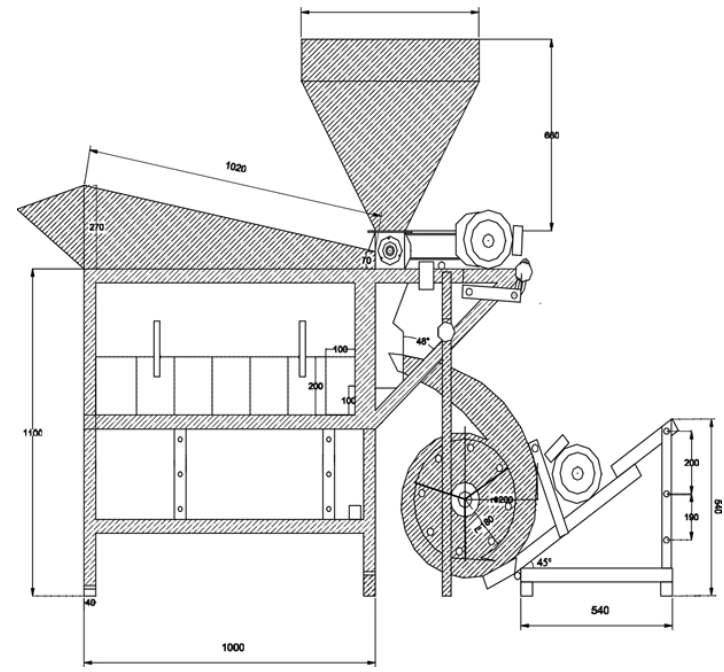

Şekil 1. Yatay hava tüneli

Besleme ünitesinin materyal giriş açıklığ $600 \times 600$ mm, materyal çıkış açıklığı 100x200 mm ve yüksekliği $550 \mathrm{~mm}$ 'dir. Materyalin çıkış ağzı, besleme esnasında oluşabilecek tıkanmaları önlemek ve tekdüze bir akış sağlamak amacıyla hücreli boşaltıcı ile desteklenmiştir. Besleme ünitesine işlevini kazandıran hücreli boşaltıcı hareketini kademeli zincir dişliden almakta olup, güç kaynağı olarak $0.75 \mathrm{~kW}$ redüktörlü trifaze elektirik motoru kullanılmıştır.

Temizleme ünitesi, 100x200 mm ölçülerinde 7 adet eş ürün dökülme kabından oluşmakta olup, besleme ünitesinden temizleme ünitesine iletilen materyale kolayca ulaşabilmesi için yan tarafina çıkarılıp takılabilen bir kapak ilave edilmiştir. Vantilatörün, temizleme ünitesine ilettiği havanın ünite içerisinde türbülans oluşturmaması için, ünitenin üst kısmı materyalin üniteyi terk ettiği uç noktaya doğru açısı artan sacdan tünelle kapatılmıştır.

Denemelerde kullanılan farklı hava hızlarını elde etmek için vantilatörün devir sayıları, giriş gerilimi 380$480 \mathrm{~V} \pm \% 10,50-60 \mathrm{~Hz} \pm \% 5$ olan frekans dönüştürücü kullanılarak değiştirilmiştir. Devir sayısının kabaca ayarı el ile hassas ayarı ise frekans dönüştürücü ile yapılmıştır. Vantilatörün yatay hava tüneli ile açısı $45^{\circ}$ ve yatay hava tünelinin yerden yüksekliği $10 \mathrm{~cm}$ 'dir. 
Bitkisel materyalin ağırlıklarını ölçmek için $6100 \mathrm{~g}$ kapasiteli ve $0.01 \mathrm{~g}$ hassasiyetli dijital terazi kullanılmıştır. Vantilatörden istenilen hızların tespiti için dijital göstergeli anemometre kullanılmıştır.

\subsection{Yöntem}

Denemeler beș farklı hava hızında (25-30-35-40-45 ms $\left.{ }^{1}\right)$, dört farklı besleme miktarında (500-750-1000-1250 $\mathrm{kgh}^{-1}$ ) ve 2 farklı materyal karışımında (A, \% 6'lık materyal karışımı, B, \% 10'luk materyal karışımı) 3 tekerrürlü olarak yürütülmüştür. Besleme ünitesinin kapasitesi $7 \mathrm{~kg}$ olup, A karışımı \% 6 taş (420 g), \% 6 toprak $(420 \mathrm{~g}), \% 88$ tane findık, tekli, ikili, üçlü çotanak ve boş zuruf $(6160 \mathrm{~g})$ ve B karışımı, \% 8 taş $(700 \mathrm{~g}), \% 8$ toprak $(700 \mathrm{~g}), \% 84$ tane findik, tekli, ikili, üçlü çotanak ve boş zuruf (5600 g) şeklindedir.

Taş ve toprak temizleme etkinliğini ve kayıp findık oranını belirleyebilmek için ünitenin her bir dökülme kutusuna düşen taş, toprak ve findık ayrı ayrı tartılmış ve aşağıdaki eşitliklerle hesaplanmıştır (Eşitlik 1).

$T E=\frac{G_{0}}{G_{1}} \times 100$

Burada;

TE: temizleme etkinliği (\%),

$\mathrm{G}_{0}$ : her bir ürün dökülme kutusundaki taş ve toprak ağırlı̆ğ (g)

$\mathrm{G}_{1}$ : Besleme ünitesinde bulunan toplam taş ve toprak ağırlığı $(\mathrm{g})$

Findık kayıp oranı, tane findık esas alınarak benzer şekilde aşağıda verilen eşitlik yardımı ile hesaplanmıştır (Eşitlik 2).

$F K O=\frac{G_{i}}{G_{w}} \times 100$

Burada;

FKO: tane findık kayıp oranı (\%)

$\mathrm{G}_{\mathrm{i}}$ : her bir ürün dökülme kutusunda bulunan tane findık ağırlı̆g $1(\mathrm{~g})$

$\mathrm{G}_{\mathrm{w}}$ : besleme ünitesinde bulunan toplam tane findık ağırlığ $1(\mathrm{~g})$

\section{Bulgular ve Tartışma}

3.1. A karışımı için hava hızı ve ürün dökülme mesafesine bağl taş ve toprak temizleme etkinliği ve findık kayıp oranı değişimleri

Yatay hava tünelinde, materyallerin farkl aerodinamik özelliklerinden faydalanarak, findık, taş ve toprak karışımından taş ve toprağın temizlenmesi amaciyla yapılan denemelerde hava hızı ve ürün dökülme mesafesinin interaktif etkilerinin, temizlenme etkinliğine etkisinin çok önemli düzeyde olduğu belirlenmiştir $(\mathrm{P}<0.01)$. A karışımı için, tüm besleme miktarları, hava hızları ve ürün dökülme mesafelerinde elde edilen taş temizleme etkinliği değerleri Şekil 2'de, toprak temizleme etkinliği değerleri Şekil 3 'te ve findık kayıp oranı değerleri şekil 4'de verilmiştir. Şekil 2'de görüldügü gibi, taş temizleme etkinliği, düşük ürün dökülme mesafelerinde, hava hızındaki artışla önemli düzeyde azalırken, ürün dökülme mesafesi arttıkça hava hızındaki artışın, taş temizleme etkinliği üzerindeki etkisi önemli düzeyde azalmıştır $(\mathrm{P}<0.01)$. A karışımı için tüm besleme miktarlarında elde edilen taş temizleme etkinliği değerlerinin, hava hızı ve ürün dökülme mesafesine bağlı olarak değişimi [hava hızı (v, $\left.\mathrm{ms}^{-1}\right)$ ve ürün dökülme mesafesine $(\mathrm{m}, \mathrm{cm})$ bağlı olarak, taş temizleme etkinliği (TEtaş, \%) için geliştirilen eşitlikler sırasıyla;

$500 \mathbf{k g h}^{-1}$, TEtaş $=0.5264+0.00385(v \cdot m)-0.00042\left(v^{2}\right)$, $R^{2}=0.86, P<0.01, n=40$, standart hata katsayllarl sirasiyla, $0.089^{* *}, 0.0003^{* *}, 6.62 \times 10^{-5 * *}$,

$750 \mathbf{~ k g h}^{-1}$, TEtaş $=0.298934+0.00776$ (v.m) -0.00028 $\left(v^{2}\right)-0.001\left(v^{2} m\right), R^{2}=0.97, P<0.01, n=40$, standart hata katsayllarl sirasiyla, $0.1321^{* * *}, 0.00154^{* *}, 9.68 \times 10^{-5 * * *}, 4.02 \times 10^{-}$ $5^{*}$,

$1000 \mathbf{k g h}^{-1}$, TEtas $=0.3239032+0.007713(\mathrm{v} . \mathrm{m})-$ $0.0033\left(v^{2}\right)-0.0001\left(v^{2} m\right), R^{2}=0.92, P<0.01, n=40$, standart hata katsayllarl sirasiyla, $0.144^{* *}, 0.0016^{* *}, 0.0001,4.10 \times 10^{-5 *}$,

$1250 \mathbf{k g h}^{-1},$. TEtas $=0.917341-0.00072\left(v^{2}\right)-0.0000954$ $\left(v^{2} . m\right), R^{2}=0.87, P<0.01, n=40$, standart hata katsayllarl sirasiyla, $\quad 0.083^{* *}, \quad 7.5 \times 10^{-5 * *}, \quad 9.68 \times 10^{-6 * *}, \quad C^{* *}: P<0.01$, ":P<0.05)]

Toprak temizleme etkinliğinin incelendiği Şekil 3'te görüldügü gibi, yakın ürün dökülme mesafelerinde, hava hızındaki artış toprak temizleme etkinliğini azaltırken, besleme miktarının da artması ile toprak temizleme miktarındaki azalış belirgin olarak artmıştır. Hava hızındaki artış, toprak temizleme etkinliğini uzak ürün dökülme mesafelerinde önemli düzeyde azaltmıştır. Şekil 3'te görülen, A karışımı için tüm besleme miktarlarında elde edilen toprak temizleme etkinliği değerlerinin, hava hızı ve ürün dökülme mesafesine bağlı olarak değişimi [hava hızı $\left(\mathrm{v}, \mathrm{ms}^{-1}\right)$ ve ürün dökülme mesafesine $(\mathrm{m}, \mathrm{cm})$ bağlı olarak, taş temizleme etkinliği $\left(\mathrm{TE}_{\text {toprak}}, \%\right)$ için geliştirilen eşitlikler sırasıyla;

$500 \mathbf{k g h}^{-1}$, TEtoprak $=0.5944+0.00038$ (v.m) -0.00057 $\left(v^{2}\right), \quad R^{2}=0.90, \quad P<0.01, \quad n=40, \quad$ standart hata katsaylarl sirasiyla, $0.081^{* *}, 0.00034^{* *}, 6.04 \times 10^{-5 * *}$,

$750 \mathbf{~ k g h}^{-1}$, TEtoprak $=0.41616+0.03579(\mathrm{v} . \mathrm{m})-0.00046$ $\left(v^{2}\right), \quad R^{2}=0.90, \quad P<0.01, \quad n=40, \quad$ standart hata katsaylarl sirasiyla, $0.0708^{* * *}, 0.00029^{* *}, 5.25 \times 10^{-5 * *}$,

$1000 \mathbf{k g h}^{-1}, \quad$ TEtoprak $=0.001147\left(v^{2} . m\right)+0.00002\left(v^{2}\right.$ .$\left.m^{2}\right), \quad R^{2}=0.90, \quad P<0.01, \quad n=40, \quad$ standart hata katsaylarl sirasiyla, $9.47 \times 10^{-5 * *}, 2.47 \times 10^{-5 * *}$,

$1250 \mathrm{kgh}^{-1}$, TEtoprak $=0.008311(v . m)-0.00016\left(v^{2}\right)-$ $0.00013\left(v^{2} . m\right), \quad R^{2}=0.94, \quad P<0.01, \quad n=40$, standart hata katsayllarl sirasiyla, $0.00078^{* * *}, 3.93 \times 10^{-5 * *}, 2.15 \times 10^{-6 * *}$, $\left.\left.{ }^{* *}: P<0.01,{ }^{*}: P<0.05\right)\right]$ olmuştur. 


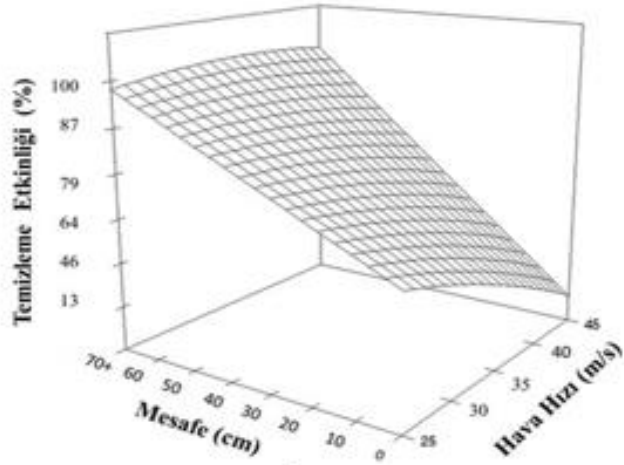

a) $500 \mathrm{kgh}^{-1}$ besleme miktarinda

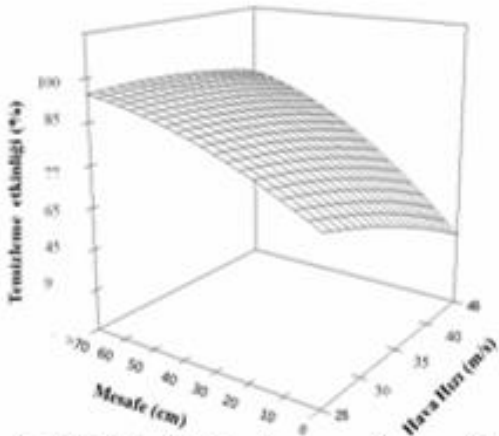

c) $1000 \mathrm{kgh}^{-1}$ besleme miktarinda

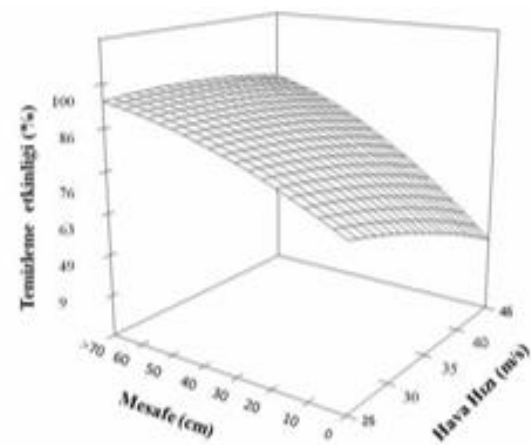

b) $750 \mathrm{kgh}^{-1}$ besleme miktarinda

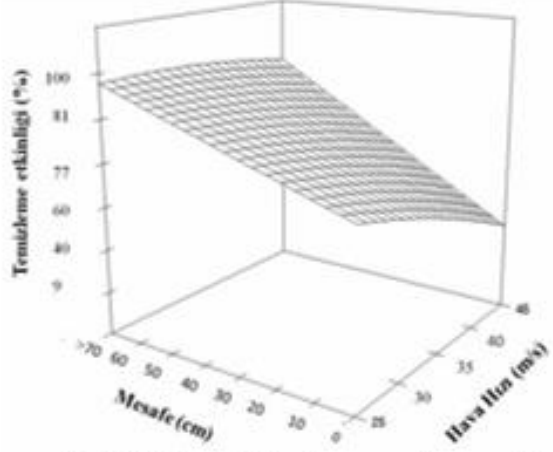

d) $1250 \mathrm{kgh}^{-1}$ besleme miktarinda

Şekil 2. A karışımı için tüm besleme miktarlarında elde edilen taş temizleme etkinliğinin, hava hızı ve ürün dökülme mesafesine bağlı olarak değişimi

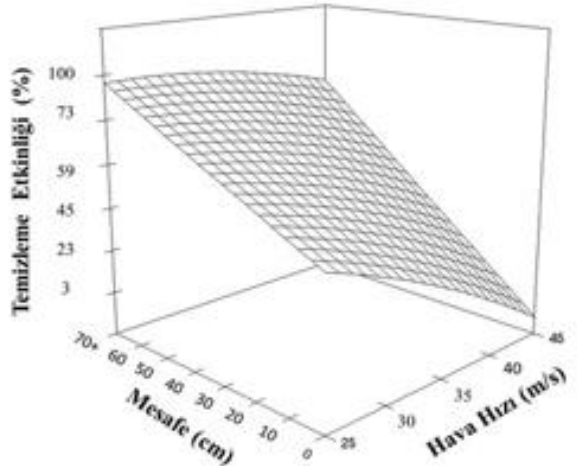

a) $500 \mathrm{kgh}^{-1}$ besleme miktarinda

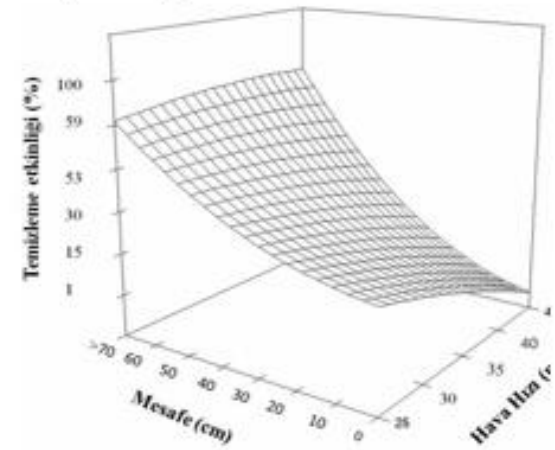

c) $1000 \mathrm{kgh}^{-1}$ besleme miktarinda

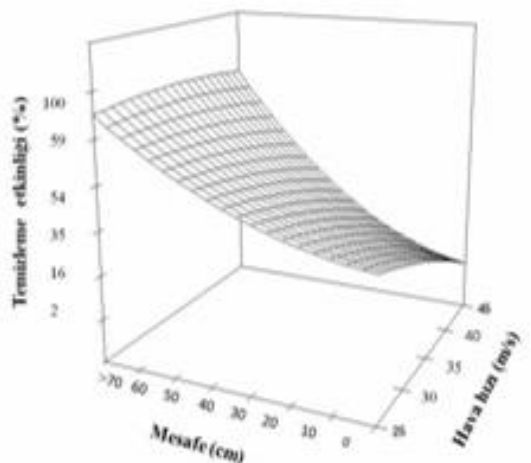

b) $750 \mathrm{kgh}^{-1}$ besleme miktarinda

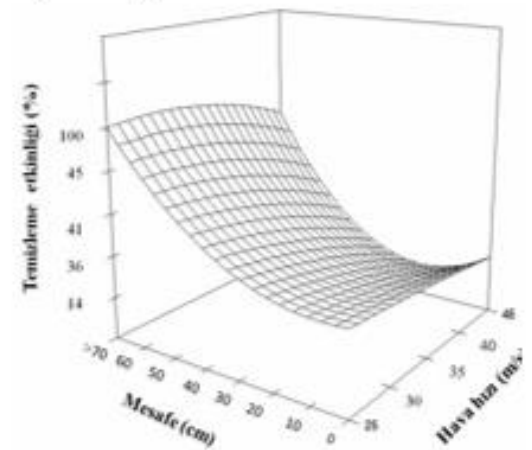

d) $1250 \mathrm{kgh}^{-1}$ besleme miktarında

Şekil 3. A karışımı için tüm besleme miktarlarında elde edilen toprak temizleme etkinliğinin, hava hızı ve ürün dökülme mesafesine bağlı olarak değişimi 


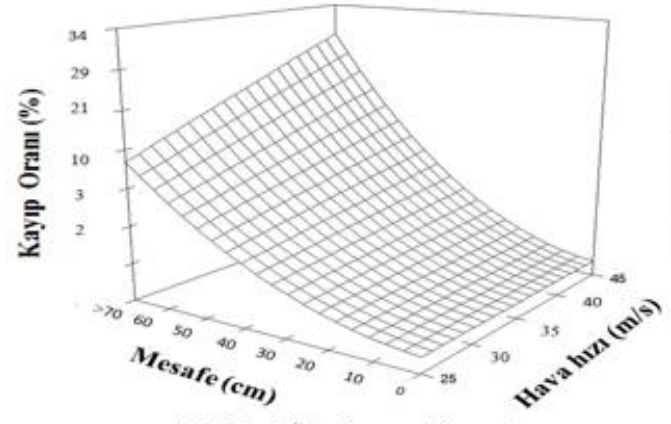

a) $500 \mathrm{kgh}^{-1}$ besleme miktarinda

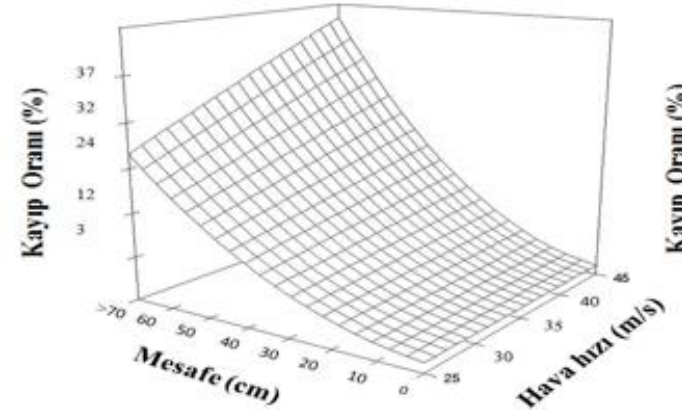

c) $1000 \mathrm{kgh}^{-1}$ besleme miktarinda

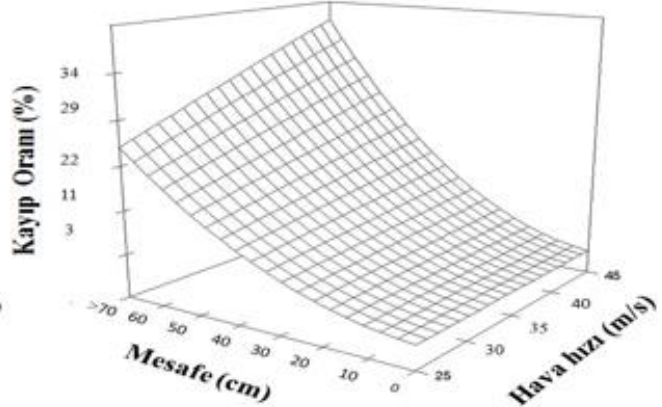

b) $750 \mathrm{kgh}^{-1}$ besleme miktarında

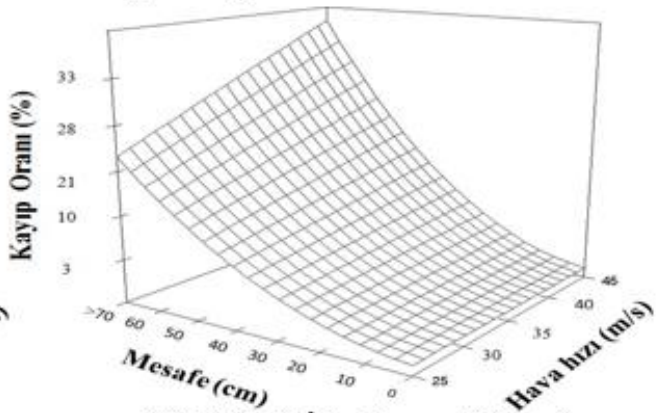

d) $1250 \mathrm{kgh}^{-1}$ besleme miktarinda

Şekil 4. A karışımı için tüm besleme miktarlarında elde edilen fındık kayıp oranının, hızı ve ürün dökülme mesafesine bağlı olarak değişimi

Şekil 4'de findık kayıp oranı değerleri görülmektedir. Buna göre, tüm faktörlerdeki değişimler için fındık kayıp oranı değerlerinin benzer olduğu görülmüştür. Hava hızındaki artış, düşük ürün dökülme mesafelerinde findık kayıp oranında belirgin bir fark yaratmazken, uzak ürün dökülme mesafelerinde hava hızının artması findık kayıp oranını çok önemli düzeyde arttırmıştır. Şekil 4'te görülen A karışımı için tüm besleme miktarlarında elde edilen findık kayıp oranı değerlerinin, hava hızı ve ürün dökülme mesafesine bağlı olarak değişimi [hava hızı $\left(\mathrm{v}, \mathrm{ms}^{-1}\right)$ ve ürün dökülme mesafesine $(\mathrm{m}, \mathrm{cm})$ bağlı olarak, taş temizleme etkinliği (FKO, \% ) için geliştirilen eşitlikler sırasıyla

$500 \mathrm{kgh}^{-1}, \quad F K O=0.172984+0.000852 *\left(\mathrm{~m}^{2} . v\right)-$ $0.00011 *\left(v^{2} . m\right) \quad R^{2}=0.91, \quad P<0.01, \quad n=40$, standart hata katsayllarl sirastyla, $0.031^{* * *}, 4.92 \times 10^{-5 * *}, 9.91 \times 10^{-6^{* * *}}$,

$750 \mathrm{kgh}^{-1}, F K O=0.08168937+0.00031853\left(\mathrm{~m}^{2} . v\right)-$ $0.000004528\left(v^{2} . m\right), R^{2}=0.81, P<0.01, n=40$, standart hata katsayllarl sirasiyla, $0.013,2.76 \times 10^{-5 * *}, 4.90 \times 10^{-5 * *}$

$1000 \mathrm{kgh}^{-1}, F K O=0.06056131+0.00068101\left(\mathrm{~m}^{2} . v\right)-$ $0.00000820\left(v^{2} . m\right), R^{2}=0.78, P<0.01, n=40$, standart hata katsayllarl strastyla, $0.044,7.01 \times 10^{-5^{* *}}, 1.41 \times 10^{-5 * *}$,

$1250 \mathrm{kgh}^{-1}, F K O=0.06385818+0.00068909\left(\mathrm{~m}^{2} . v\right)-$ 0.00000681 (v2.m), $R^{2}=0.92, P<0.01, n=40$, standart hata katsayllarl sirastyla, $0.047,7.50 \times 10^{-5^{* *}}, 1.51 \times 10^{-5^{* *}} \mathrm{dir}$. $\left.\left(^{* *}: P<0.01, *: P<0.05\right)\right]$

\subsection{B karlşımı için hava hızı ve ürün dökülme mesafesine bağlı taş ve toprak temizleme etkinliği ve findık kayıp oranı değisşimleri}

Yatay hava tünelinde, materyallerin farklı aerodinamik özelliklerinden faydalanarak, fındık, taş ve toprak karışımından taş ve toprağın temizlenmesi amaciyla yapılan denemelerde hava hızı ve ürün dökülme mesafesinin interaktif etkilerinin, temizlenme etkinliğine etkisinin çok önemli düzeyde olduğu belirlenmiştir $(\mathrm{P}<0.01)$. Tüm besleme miktarları, hava hızları ve ürün dökülme mesafelerinde elde edilen taş temizleme etkinliği değerleri Şekil 5'te, toprak temizleme etkinliği değerleri Şekil 6'da ve findık kayıp oranı değerleri şekil 7'de verilmiştir.

Şekil 5'te görüldüğü gibi, B karışımı için taş temizleme etkinliği değerleri incelendiğinde, hava hızındaki artış, 500-750 $\mathrm{kgh}^{-1}$ besleme miktarlarında, düşük ürün dökülme mesafelerinde taş temizleme etkinliğini çok önemli düzeyde azaltırken, 1000-1250 $\mathrm{kgh}^{-1}$ besleme miktarlarında taş temizleme etkinliği, dökülme mesafesi arttıkça hava hızındaki artışla önemli düzeyde azalmıştır. Şekil 5'te görülen B karışımı için tüm besleme miktarlarında elde edilen taş temizleme etkinliği değerlerinin, hava hızı ve ürün dökülme mesafesine bağlı olarak değişimi [hava hızı $\left(\mathrm{v}, \mathrm{ms}^{-1}\right)$ ve ürün dökülme mesafesine $(\mathrm{m}, \mathrm{cm})$ bağlı olarak, taş temizleme etkinliği ( $\left.\mathrm{TE}_{\text {taş }}, \%\right)$ için geliştirilen eşitlikler sirasiyla; 


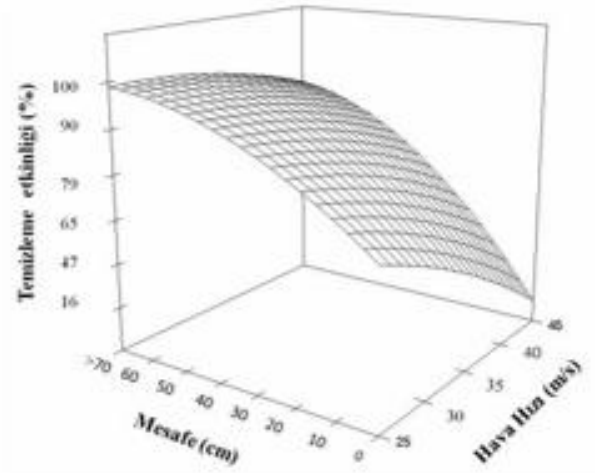

a) $500 \mathrm{kgh}^{-1}$ besleme miktarında

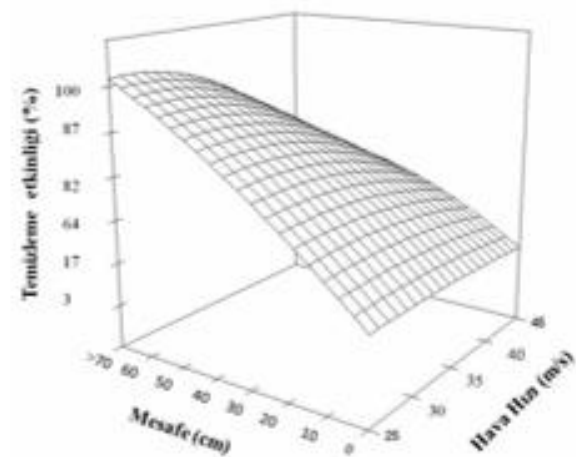

c) $1000 \mathrm{kgh}^{-1}$ besleme miktarinda

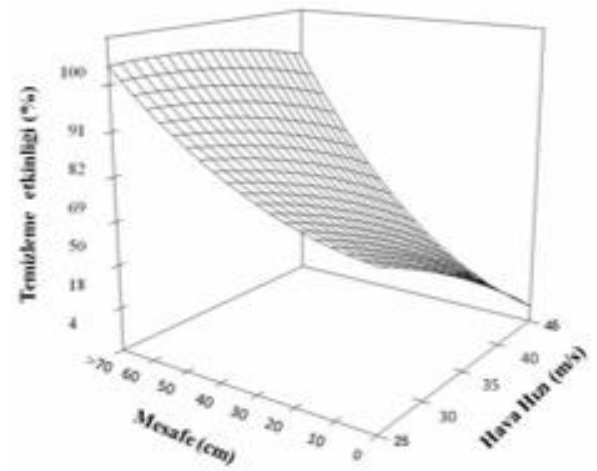

b) $750 \mathrm{kgh}^{-1}$ besleme miktarında

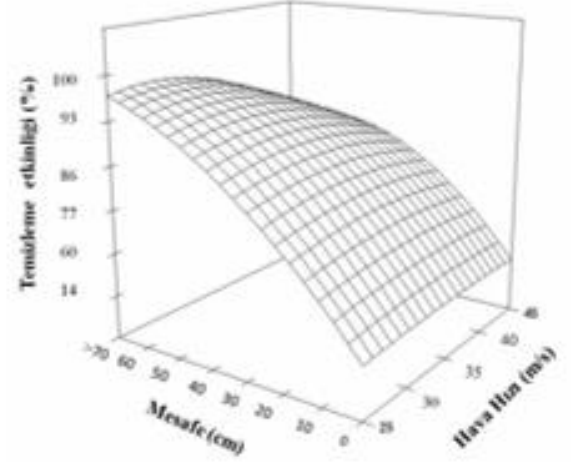

d) $1250 \mathrm{kgh}^{-1}$ besleme miktarında

Şekil 5. B karışımı için tüm besleme miktarlarında elde edilen taş temizleme etkinliğinin hızı ve ürün dökülme mesafesine bağlı olarak değişimi

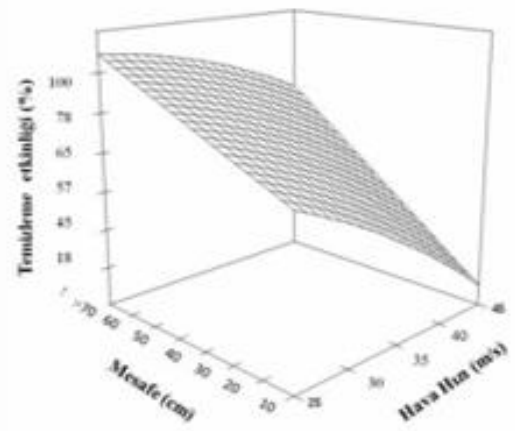

a) $500 \mathrm{kgh}^{-1}$ besleme miktarinda

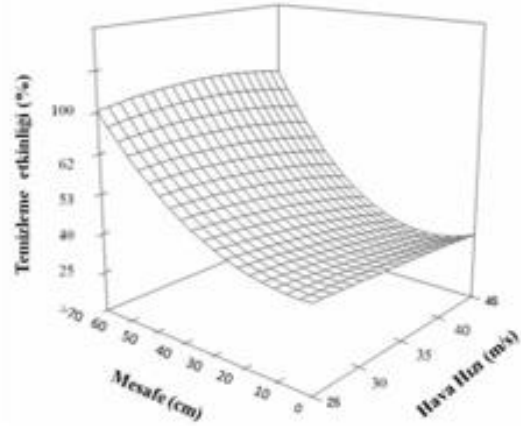

c) $1000 \mathrm{kgh}^{-1}$ besleme miktarinda

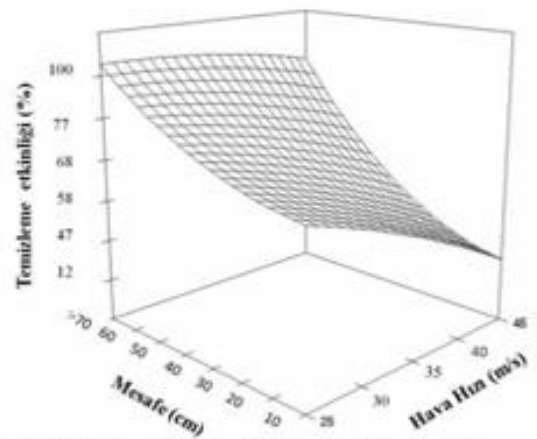

b) $750 \mathrm{kgh}^{-1}$ besleme miktarinda

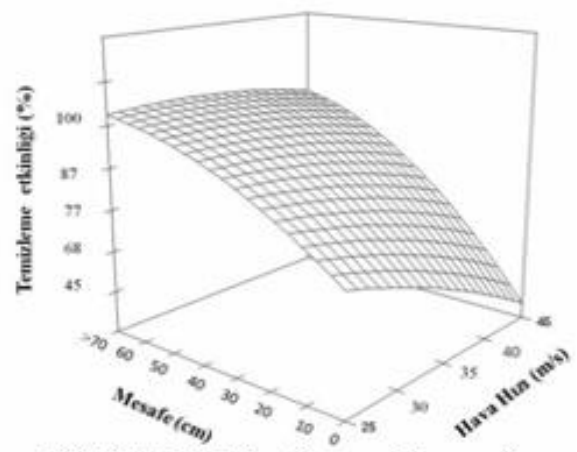

d) $1250 \mathrm{kgh}^{-1}$ besleme miktarinda

Şekil 6. B karışımı için tüm besleme miktarlarında elde edilen toprak temizleme etkinliğinin hızı ve ürün dökülme mesafesine bağlı olarak değişimi 
$500 \mathbf{k g h}^{-1}, T E_{t a s}=0.018807(v . m)-0.00025\left(v^{2}\right)-0.0187$ $\left(m^{2}\right)-0.00027\left(v^{2} . m\right), R^{2}=0.98, P<0.01, n=40$, standart hata katsayllarl sirasiyla, $0.0014^{* *}, 4.72 \times 10^{-5 * *}, 0.0035^{* *}, 2.06 \times 10^{-}$ $6^{*}$,

$750 \mathbf{k g h}^{-1}$, TEtaş $=0.705738-0.003844$ (v.m) - 0.00054 $\left(v^{2}\right), \quad R^{2}=0.91, \quad P<0.01, \quad n=40, \quad$ standart hata katsayllarl sirasiyla, $0.07076^{* *}, 0.00029^{* *}, 5.25 \times 10^{-6 * *}$,

$1000 \mathbf{k g h}^{-1}, \quad$ TEtaş $=0.392632-0.007946(v . m)-0.0034$ $\left(v^{2}\right)-0.00011\left(v^{2} . m\right), R^{2}=0.93, P<0.01, n=40$, standart hata katsayllarl sirasiyla, $0.1404^{* *}, 0.0016^{* *}, 0.00010,4.27 \times 10^{-6 * *}$,

$1250 \mathbf{~ k g h}^{-1}$, TEtaş $=0.392632-0.007946(v . m)-0.0034$ $\left(v^{2}\right)-0.00011\left(v^{2} . m\right), R^{2}=0.93, P<0.01, n=40$, standart hata katsaylarl sirasiyla, $0.1404^{* *}, 0.0016^{* *}, 0.00010,4.27 \times 10^{-6^{* *}}$, $\left.\left(^{* *}: P<0.01, *: P<0.05\right)\right]$ olmuştur.

Şekil 6'da görüldüğü gibi en düşük besleme miktarında ve düşük ve yüksek ürün dökülme mesafelerinde, hava hızındaki artış, toprak temizleme etkinliğini çok önemli düzeyde azaltırken, besleme miktarı ve ürün dökülme mesafesi arttıkça, hava hızındaki artışın, toprak temizleme etkinliğine belirgin düzeyde bir etkisi olmamıştır. Şekil 6'da görülen B karışımı için tüm besleme miktarlarında elde edilen toprak temizleme etkinliği değerlerinin, hava hızı ve ürün dökülme mesafesine bağlı olarak değişimi [hava hızı $\left(\mathrm{v}, \mathrm{ms}^{-1}\right)$ ve ürün dökülme mesafesine $(\mathrm{m}, \mathrm{cm})$ bağlı olarak, taş temizleme etkinliği $\left(\mathrm{TE}_{\text {toprak }}, \%\right)$ için geliştirilen eşitlikler sırasıyla;

$500 \mathbf{k g h}^{-1}$, TEtoprak $=0.382686+0.00013\left(v^{2} . m\right)+$ $0.000911\left(m^{2} . v\right), R^{2}=0.86, P<0.01, n=40$, standart hata katsayllarl sirastyla, $0.0059^{* *}, 1.87 \times 10^{-5^{* *}}, 9.3 \times 10^{-5 * *}$,

$750 \mathbf{k g h}^{-1}$, TEtoprak $=0.821624-0.0007\left(v^{2} . m\right)+$ $0.00008931\left(v^{2} . m\right), R^{2}=0.85, P<0.01, n=40$, standart hata katsayllarl sirasiyla, $0.0852^{* *}, 7.65 \times 10^{-5 * *}, 9.87 \times 10^{-5 * *}$,

$1000 \mathbf{~ k g h}^{-1}$, TEtoprak $=1.05075-0.03464(\mathrm{v})+$ $0.003488(v . m), R^{2}=0.89, P<0.01, n=40$, standart hata katsayllart sirasiyla, $0.1290^{* *}, 0.0038,0.00031^{* *}$,

$1250 \mathbf{k g h}^{-1},$. TEtoprak $=1.05075-0.03464(v)+$ $0.003488(v . m), R^{2}=0.89, P<0.01, n=40$, standart hata katsayllarl sirastyla, $0.1290^{* *}, 0.0038,0.00031^{* *}$, $\left.\left(^{* *}: P<0.01, *: P<0.05\right)\right]$.

Yine Şekil 7'de fındık kayıp oranı değerleri görülmektedir. Buna göre, ürün dökülme mesafesi ve hava hızındaki artışa bağlı olarak findık kayıp oranı önemli düzeyde artmıştır. Şekil 7'de görülen B karışımı için tüm besleme miktarlarında elde edilen findık kayıp oranı değerlerinin, hava hızı ve ürün dökülme mesafesine bağlı olarak değişimi [hava hızı $\left(\mathrm{v}, \mathrm{ms}^{-1}\right)$ ve ürün dökülme mesafesine $(\mathrm{m}, \mathrm{cm})$ bağ ${ }_{1}$ olarak, taş temizleme etkinliği (FKO, \% ) için geliştirilen eşitlikler sırasıyla;

$500 \mathrm{kgh}^{-1}, \quad F K O=0.093473+0.00069\left(\mathrm{~m}^{2} \cdot \mathrm{v}\right)-$ $0.0000084\left(\mathrm{~m}^{2} . v\right) R^{2}=0.81, P<0.01, n=40$, standart hata katsayllarl sirasiyla, $0.040^{* *}, 6.44 \times 10^{-5 * *}, 1.3 \times 10^{-5 * *}$,
$750 \mathrm{kgh}^{-1}, F K O=0.517661-0.00038\left(v^{2}\right)+0.000452$ $\left(m^{2} . v\right), R^{2}=0.86, P<0.01, n=40$, standart hata katsayllar sirasiyla, $0.066^{* *}, 4.87 \times 10^{-5^{* *}}, 3.12 \times 10^{-5^{* *}}$,

$1000 \mathrm{kgh}^{-1}, F K O=0.091846+0.000689\left(\mathrm{~m}^{2} . v\right)$ $0.0000082\left(v^{2} . m\right), R^{2}=0.84, P<0.01, n=40$, standart hata katsayllarl strasiyla, $0.037^{* *}, 5.9 \times 10^{-5 * *}, 1.19 \times 10^{-5 * *}$,

$1250 \mathbf{~ k g h}^{-1}, F K O=0.09203753+0.0006904\left(\mathrm{~m}^{2} . v\right)-$ $0.000008357\left(v^{2} . m\right), R^{2}=0.83, P<0.01, n=40$, standart hata katsayllarl strastyla, $0.038^{* *}, 6.11 \times 10^{-5 * *}, 1.23 \times 10^{-}$ $\left.\left.5^{* *} \operatorname{dir} .{ }^{* *}: P<0.01, *: P<0.05\right)\right]$ olmuştur.

B karışımı için tüm besleme miktarları, hava hızları ve ürün dökülme mesafelerinde, taş ve toprak temizleme etkinliğinin maksimum, findık kayıp oranının minimum olduğu uygulamalar $25-30 \mathrm{~ms}^{-1}$ hava hızı ve $30-40 \mathrm{~cm}$ ürün dökülme mesafelerinde elde edilmiştir. Bu değerler için taş temizleme etkinliği \% 64-\% 94 aralığında, toprak temizleme etkinliği $\% 30-\% \quad 100$ aralı̆̆ında ve findık kayıp oranı \% 1-\% 19 aralığında elde edilmiş̧ir.

Ayrıca tüm karışım oranı, besleme miktarı ve hava hızlarında tekli, ikili, üçlü çotanaklar ve boş zuruflar ünite dışına sürüklenmiş ve tane findıktan tamamen temizlenebilmiştir. Toprak parçalarının yüzeylerinin girintili çıkıntılı ve pürüzlü olmasına bağlı olarak aerodinamik sürüklenme katsayısını yüksek olması tüm parametreler için toprak temizleme etkinliğinin taş temizleme etkinliğinden düşük olmasına sebep olmuştur.

\section{Sonuç}

Yatay hava tüneli kullanılarak yapılan çalışmalarda, işletme parametrelerinden olan ürün dökülme mesafesi ve hava hızı değerlerinin, taş ve toprak temizleme etkinliğine ve findık kayıp oranına etkisi önemli düzeyde bulunmuştur.

Hasat sirasinda yerden toplanan materyal karışımındaki taş ve toprak yoğunluğu kontrol edilemeyeceği için, temizleme etkinliği için hava hızı ve ürün dökülme mesafesi kritik önem taşımaktadır. Buna göre her iki karışım içinde taş ve toprak temizleme etkinliği hava hızının artmasıyla azalmış, ürün dökülme mesafesinin artmasıyla artmıştır. Ürün dökülme mesafesindeki artış taş ve toprak temizleme etkinliğini arttırmakla beraber kayıp findık oranını da arttırmıştır. Toprak temizleme etkinliği tüm uygulamalar için taş temizleme etkinliğinden düşük bulunmuştur.

Temizleme etkinliğinin arttırılması ve daha düşük hava hızlarında da temizleme sağlanabilmesi için, $40 \mathrm{~cm}$ ürün dökülme uzaklığında toplama kaplarında ayrılan materyal karışımının ikinci bir seperasyon düzeneği ile ayrılma olanağı araştırılabilir. Farklı temizleme sistemlerinin de araştırılması uygulama alanında etkili bir sistemin geliştirilebilmesi açısından faydalı olabilecektir. 


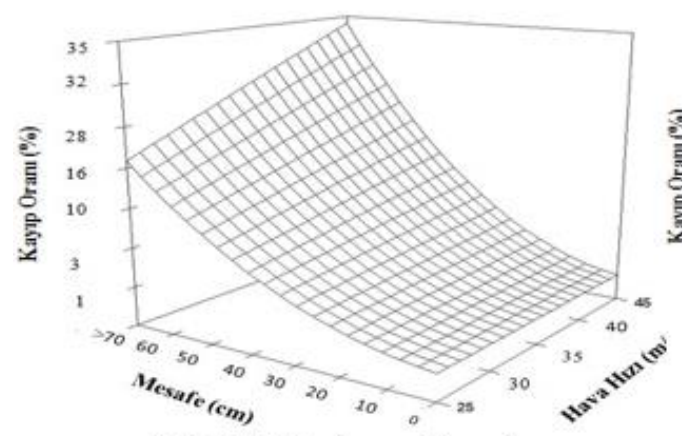

a) $500 \mathrm{kgh}^{-1}$ besleme miktarinda

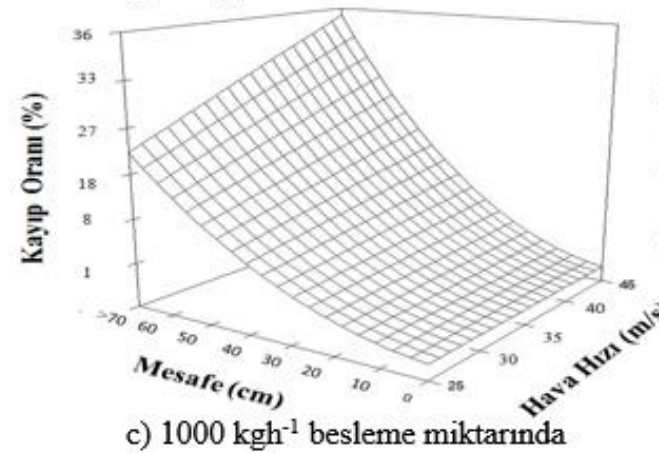

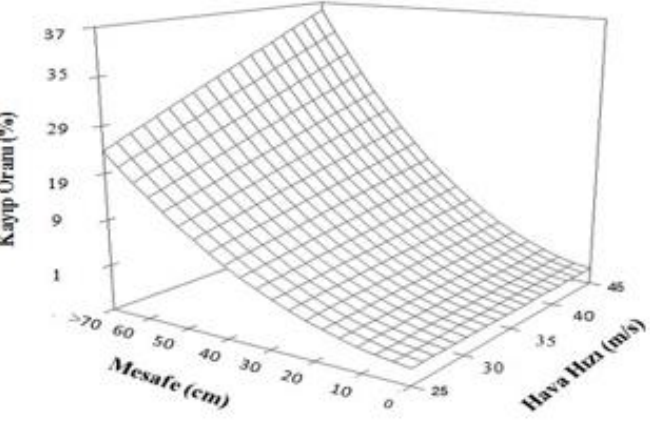

b) $750 \mathrm{kgh}^{-1}$ besleme miktarinda

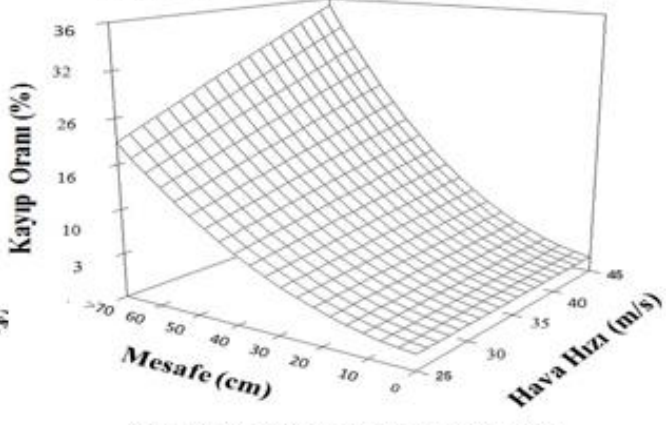

d) $1250 \mathrm{kgh}^{-1}$ besleme miktarinda

Şekil 7. B karışımı için tüm besleme miktarlarında elde edilen findık kayıp oranının hızı ve ürün dökülme mesafesine bağlı olarak değişimi

\section{Kaynaklar}

Anonim, 2014. Food and Agriculture Organization of the United Nations. (Erişim Tarihi: 09.07.2014)

Beyhan, M.A, 1992. Ülkemiz koşullarına uygun aspiratörlü bir findık hasat makinesi tasarım ve imalatı. Doktora Tezi. Ankara Üniversitesi Fen Bilimleri Enstitüsü, Ankara.

Bozoğlu, M., 1999. Türkiye'de findık piyasalarını geliştirmeye yönelik alternatif politikalar üzerine bir araştırma. Doktora Tezi (Basılmamış). A. Ü. Fen Bilimleri Enstitüsü Tarım Ekonomisi Anabilim Dalı, Ankara.
Sarig. Y., Emek, M., Orny, R., ,1974,. The development of side-delivery pecan sweeper. Transaction of the ASAE, 17 (3): 474-476.

Sauk, H., 2017. Türkiye'de düz ve düze yakın arazilerde yetiştirilen findığın mekanik hasat olanaklarının incelenmesi. Doktora Tezi. Ondokuz Mayıs Üniversitesi Fen Bilimleri Enstitüsü, 89 s., Samsun.

Simonyan, K. J., Yiljep, Y. D, 2008. Investing grain separation and cleaning efficiency distribution of a conventional stationary rasp-bar sorghum thresher, Agricultural Engineering International; The CIGR Ejournal Manuscript PM 07028. Vol. X, 1- 13. 